\title{
Right Ventricular Plasticity
}

Hector I. Michelena and Rowlens Melduni

Key words: right ventricle, pulmonary hypertension

(Inter Med 47: 1443-1444, 2008)

(DOI: 10.2169/internalmedicine.47.1274)

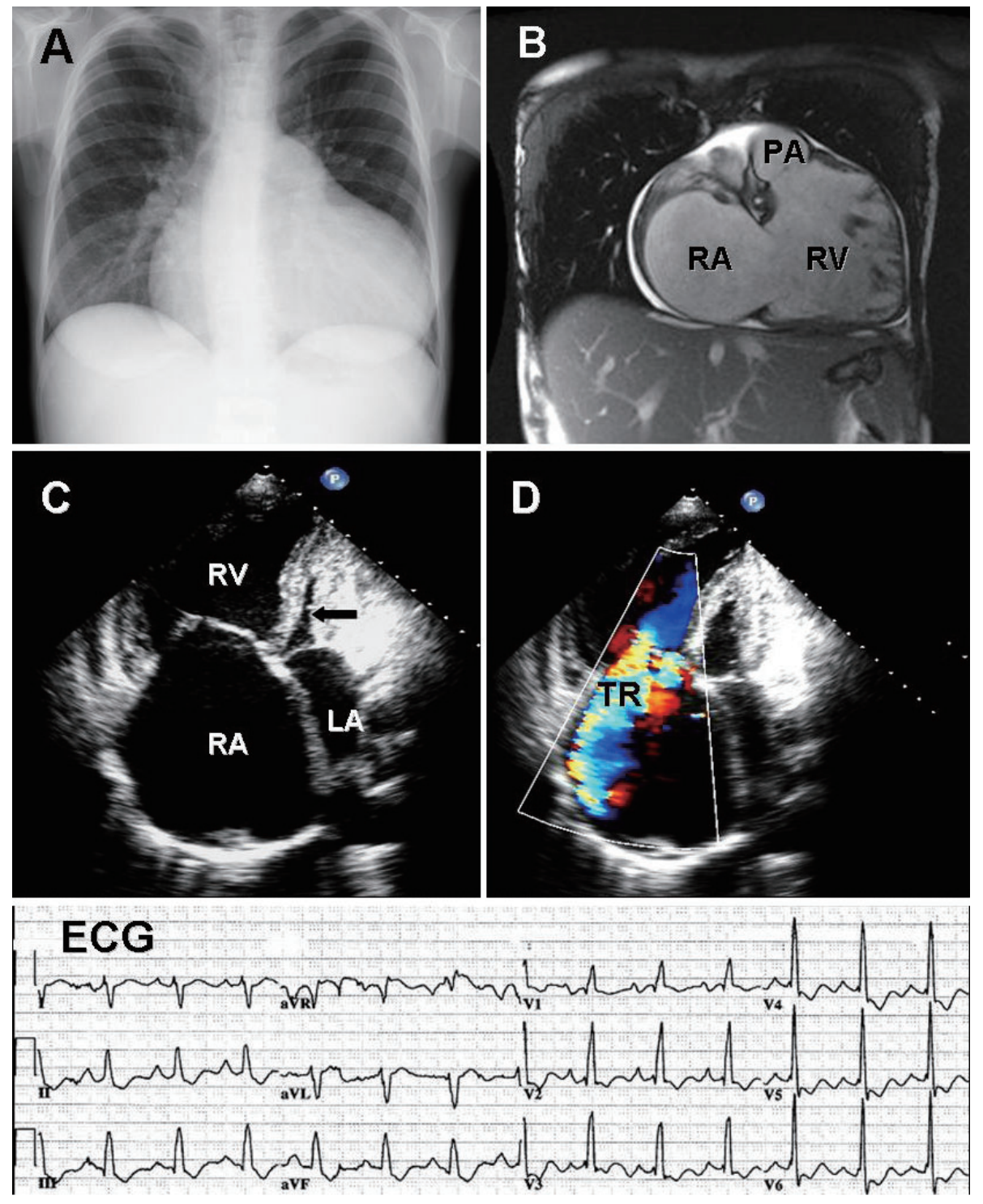

A 37-year-old woman with primary pulmonary hypertension since the age of 30 , presented with worsening dyspnea on exertion and hypotension. Physical examination revealed jugular venous distention, right ventricular heave, increased 
intensity of P2, 3/6 holosystolic murmur, abdominal flank dullness to percussion and minimal peripheral edema. A chest film revealed severe cardiomegaly (A). Electrocardiogram (ECG) showed complete right bundle branch block with right atrial and ventricular hypertrophy. Apical 4chamber view of a transthoracic echocardiogram (C) showed massive right atrial (RA) and right ventricular (RV) enlargement with severe compression of the left ventricle in systole (arrow) and a normal left atrium (LA) with right ventricular systolic pressure of $112 \mathrm{mmHg}$. Torrential tricuspid regurgitation (TR) was evident by color-flow Doppler in systole (D). Magnetic resonance imaging (B) revealed a prominent pulmonary artery (PA) with severe RA and RV enlargement and hypertrophy with RV ejection fraction of $23 \%$ (normal $53-73 \%$ ) and RV end-diastolic volume indexed by BSA of $306 \mathrm{cc} / \mathrm{m}^{2}$ (normal $50-118 \mathrm{cc} / \mathrm{m}^{2}$ ). The patient is currently receiving inotropes and diuretics while awaiting heart-lung transplantation.

Severe septal shift alters left ventricular geometry (C) and is responsible in part for the presenting hypotension (1). The myocardium has a dynamic growth rate of at least $100 \%$ in response to stress (2). Decompensation is related to apoptosis, fibrosis, calcium homeostasis perturbations, and chamber dilatation, and it may be irreversible (2), such as in our patient.

\section{References}

1. Haddad F, Doyle R, Murphy DJ, Hunt SA. Right ventricular function in cardiovascular disease, Part II: Pathophysiology, clinical importance, and management of right ventricular failure. Circula- tion 117: 1717-1731, 2008.

2. Hill JA, Olson EN. Cardiac plasticity. N Engl J Med 358: 13701380, 2008.

(C) 2008 The Japanese Society of Internal Medicine http://www.naika.or.jp/imindex.html 